\title{
Technical aspects of calorie menu labelling in Ireland: stakeholder views
}

\author{
L. M. Courtney ${ }^{1}$, A. E. Bennett ${ }^{1}$, F. Douglas ${ }^{1}$, E. M. Keaveney ${ }^{1}$, É. P. Crowley ${ }^{1}$, M. A. T. Flynn ${ }^{1}$ \\ ${ }^{1}$ Public Health Nutrition, Food Safety Authority of Ireland, Dublin 1, Republic of Ireland
}

Calorie menu labelling can positively affect consumer food choice without negatively impacting business ${ }^{(1)}$. Best practice in calorie menu labelling is summarised by four technical principles where calorie information is displayed: (1) on standard food and drink items sold; (2) clearly at the 'point of choice'; (3) per portion or per meal; and (4) in terms of average daily calorie needs ${ }^{(2)}$. This study determines stakeholder views on these four principles and levels of support required for implementing calorie menu labelling in Ireland.

Draft technical guidance for implementing calorie menu labelling was provided on-line ${ }^{(3)}$. Through a four week national consultation, stakeholders (food businesses and health professionals) were invited to submit their views on the four principles via a short on-line Technical Survey. Also, during the consultation, attendees at a Hospitality Exposition were surveyed using an interviewer-assisted questionnaire. Data on gender, age, and whether calorie menu labelling should be implemented, and in which food outlets, were collected. In addition, those working in food service businesses were asked if calorie menu labelling was initiated in Ireland, would they implement it. Differences in views were analysed according to background (consultation data) and age or gender (Exposition data) using $\chi^{2}$ tests.

\begin{tabular}{|c|c|c|c|c|c|c|c|c|c|}
\hline \multirow[t]{2}{*}{ Submitters' Background } & \multirow[t]{2}{*}{ Views } & \multicolumn{2}{|c|}{ Principle (1) $n 265$} & \multicolumn{2}{|c|}{ Principle (2) $n 264$} & \multicolumn{2}{|c|}{ Principle (3) $n 262$} & \multicolumn{2}{|c|}{ Principle (4) $n 263$} \\
\hline & & $\%$ & $n$ & $\%$ & $n$ & $\%$ & $n$ & $\%$ & $n$ \\
\hline \multirow[t]{2}{*}{ Food Business } & Agree with all or some & $61 *$ & 122 & $59 *$ & 119 & $52 *$ & 103 & $51 *$ & 101 \\
\hline & Disagree with all & 38 & 76 & 40 & 80 & 47 & 93 & 47 & 94 \\
\hline \multirow[t]{2}{*}{ Health Professional } & Agree with all or some & 92 & 59 & 94 & 59 & 95 & 60 & 91 & 58 \\
\hline & Disagree with all & 6 & 4 & 5 & 3 & 5 & 3 & 9 & 6 \\
\hline
\end{tabular}

*Food Businesses $v s$. Health Professionals $p<0.001$. 'Don't know' responses not shown.

As shown in the table, the majority of submissions received in the national consultation were in support of the principles and the proposed guidance for their implementation, regardless of submitters' background. However, significantly less food businesses, compared with health professionals, agreed with all four principles $(p<0.001)$. Of over 2000 attendees at the Hospitality Exposition, 287 (53\% female; aged 18 to 55 + years) were interviewed. The majority $(73 \%)$ wanted calorie menu labelling in all or some food outlets, with significantly more females compared with males ( $79 \%$ vs. $66 \%$ respectively, $p<0.05$ ) in support of this. Of those in favour of calorie menu labelling in some outlets, most wanted it in fast food outlets $(78 \%)$, followed by cafes $(43 \%)$, coffee shops $(41 \%)$, vending machines $(41 \%)$, delis $(39 \%)$, cinema (33\%), bakery (32\%), pubs (29\%), and restaurants $(25 \%)$. Among those working in food service directly, more females than males would voluntarily implement calorie menu labelling $(70 \% v s .59 \%$ respectively, $p<0.05)$ if this was initiated in Ireland.

This study shows that whilst an overall majority of food businesses support the best practice principles and proposed technical implementation of calorie menu labelling in Ireland, this is more strongly supported by health professionals. Among those working in the food service sector, support may not differ according to age, but females are more likely than their male counterparts to become involved in calorie menu labelling.

1. Bollinger B, Leslie P, Sorenson A (2011) Amer Econ J 3, 91-128.

2. Food Standards Agency (2011) at: www.food.gov.uk/multimedia/pdfs/publication/fsanicaterercalorieinfopilot.pdf

3. Food Safety Authority of Ireland (2011) at: http://www.fsai.ie/WorkArea/DownloadAsset.aspx?id=11193 